\title{
Damage Cost/Value Clustering in Timber Harvesting Decision Making for Sustainable Forest Management
}

Original Scientific Paper

\author{
Hana Munira Muhd Mukhtar \\ Applied Statistics and Data Science Research Cluster, \\ Universiti Kuala Lumpur, \\ Malaysian Institute of Information Technology, \\ 1016, Jalan Sultan Ismail, 50250 Kuala Lumpur. \\ hanamunira@unikl.edu.my
}

\section{Yasmin Yahya}

Applied Statistics and Data Science Research Cluster, Universiti Kuala Lumpur,

Malaysian Institute of Information Technology, 1016, Jalan Sultan Ismail, 50250 Kuala Lumpur. yasmin@unikl.edu.my

\author{
Azizah Rahmat \\ Service and Information Science Research Cluster, \\ Universiti Kuala Lumpur, \\ Malaysian Institute of Information Technology, \\ 1016, Jalan Sultan Ismail, 50250 Kuala Lumpur. \\ azizah@unikl.edu.my
}

\section{Roslan Ismail \\ Applied Statistics and Data Science Research Cluster, Universiti Kuala Lumpur, \\ Malaysian Institute of Information Technology, 1016, Jalan Sultan Ismail, 50250 Kuala Lumpur. drroslan@unikl.edu.my}

\begin{abstract}
The most important factor to ensure forest regrowth strongly relies on minimizing damage as well as maintaining an adequate quantity and quality of residual stands. Currently, most of the Malaysian concessions are applying the Selective Management System (SMS). The SMS had been introduced about 40 years ago and various studies discovered that it contributes a negative impact on the forest. Thus, revision and adoption of an appropriate harvesting method are required. The main objective of this study is to propose a new method that promotes forest regrowth and reduces damages due to logging activities for Sustainable Forest Management (SFM). The two primary elements introduce in this new method are 1) to determine the minimum damage cost/value to the residual trees according to tree felling direction and 2) on the division of logging area into clusters where only certain clusters will be affected in a logging operation and the rest are conserved. The overall results of this study proven that the analysis of potential logged value, productions, damage value, and damage volume by dividing forest into clusters able to minimize damage and maintain forest regeneration.
\end{abstract}

Keywords: damage cost/value, tree felling direction, forest clustering algorithm

\section{INTRODUCTION}

Forests are crucial in terms of biodiversity and ecosystem, it gives numerous benefits to humans as well as timber products and biodiversity conservation. About 300 to 350 million people are directly and indirectly dependent on forests [1]. Tropical deforestation and forest degradation are some of the world's most urgent environmental problems. It contributes to biodiversity loss, accounts for approximately 17\% of total global carbon emissions, and has adverse socio-economic consequences for forest-dependent people (e.g. EU, 2016). In addition, tropical forest degradation is one of the significant factors of carbon dioxide (CO2) emission [2]-[4] approximately 2.1 billion tons of $\mathrm{CO} 2$ yearly [2]. To address this issue, one of the crucial decisions to make in forest planning and forest management is to determine the best logging operation to increase timber harvesting productivity that reduces damages and promotes forest regrowth for sustainable forest management. In this paper, we describe the newly proposed methods to promote forest regrowth and reduce damages due to logging activities for sustainable forest management. By understanding the calculation of minimum damage based on tree felling direction, we can expect to have significant results in implementing the new methods and algorithms.

This paper is organized as follows; in the next section, the related work regarding the implementation and the limitations of the Selective Management System (SMS) are presented. Then followed by Section 3 where the newly proposed algorithms on how to determine the minimum damage cost to residual trees and also forest clustering for preservation are thoroughly described. Section 4 combines the results from the selection of the best-felling direction and decision-making on the minimum damage. Finally, Section 5 and 6 presents our conclusion and acknowledgment respectively. 


\section{RELATED WORK}

Since 1978, the Selective Management System (SMS) was implemented for timber harvesting in Malaysia. This commercial logging system mainly targets dipterocarp species. Selective Management System (SMS), the current logging system is; a year before felling, commercially viable trees are marked for felling, the harvestable trees applied are $>45 \mathrm{~cm}$ dbh for non-dipterocarp, and $>50 \mathrm{~cm}$ dbh for dipterocarp species. Lat$\mathrm{er}$, arrows are painted on trees to indicate the direction of felling to avoid damaging other valuable trees. Then, the system calculates the damage volume of residual trees [5], [6]. However, this event only takes place $10 \%$ of the pre-felling inventory as sampling for the rest of the felling area [7]. These decisions play an important role in maintaining the species composition and structure of the forest [8], [9].

According to various researchers [7], [8], [10]-[13], the most important factor to ensure forest regrowth strongly relies on minimizing damage as well as maintaining an adequate quantity and quality of residual stands. These studies discovered that the current selective logging contributes negative impacts to the forest; such as frequency distribution of gap area was strongly skewed, a low recovery rate of forest conditions after logging, tree volume of non-dipterocarp species higher than dipterocarp species, and absence of large-sized mammals. Therefore, a revision of current forest management in Peninsular Malaysia, mitigation actions, and the adoption of an appropriate harvesting plan for sustainable forest management are needed.

The purpose of this study is to propose a solution that has the potential to mitigate the stated current issues corresponding to sustainable forest management practices by dividing the forest into clusters, determine potential trees to log according to clusters with minimum damage value and damage volume to the surrounding trees. The analysis of these minimum damages provides a significant impact on forest preservation. The study will produce an output of the analysis that could be used by the government for timber harvesting decision-making.

\section{MATERIALS AND METHOD}

In response to this challenge, the main objective of this study is to propose a new method that promotes forest regrowth and reduces damages due to logging activities for Sustainable Forest Management (SFM). The two primary elements introduce in this new method are 1) to determine the minimum damage cost/value to the residual trees and 2 ) forest clustering to retain areas of unlogged forest for preservation. Preserve unlogged forest is critically important to safeguard species biodiversity of the tropical rainforest [7], [14], [15].

Selective Management System (SMS) is the current method that has been implemented by the majority of Malaysian concessions. Although this method is based on SFM practices, there are some negative side effects to the forest after more than 40 years of practicing.

For the logging activities, the SMS can be categorized into 3 stages for the logging activities under the SMS system. Table 1 describes the Selective Management System (SMS) that has been employing in a Malaysian forest. One of the limitations of this practice; these activities only take place on $10 \%$ of the whole logging area. From the accuracies point of view, this $10 \%$ sampling is no longer practical. Therefore, a new method is required.

The stages and activities according to the current practice are well illustrated.

Table 1. The SMS activities

\begin{tabular}{|c|c|c|}
\hline Stage & Year & Activities \\
\hline \multirow[t]{2}{*}{ Pre-Harvesting } & $\begin{array}{l}n-2 \text { years to } \\
n-1 \text { years }\end{array}$ & $\begin{array}{l}\text { Pre-felling forest inventory } \\
\text { of } 10 \% \text { sampling intensity } \\
\text { using systematic-line plots to } \\
\text { determine appropriate cutting } \\
\text { regimes ( }>45 \mathrm{~cm} \text { dbh for non- } \\
\text { dipterocarp and }>50 \mathrm{~cm} \text { dbh for } \\
\text { dipterocarp). }\end{array}$ \\
\hline & $n-1$ year to $n$ & $\begin{array}{l}\text { Tree marking incorporating } \\
\text { directional felling. }\end{array}$ \\
\hline \multirow[t]{2}{*}{ Harvesting } & $\mathrm{n}$ & Felling all marked trees. \\
\hline & $\begin{array}{c}n+1 / 4 \text { year to } \\
n 1 / 2 \text { year }\end{array}$ & $\begin{array}{l}\text { Forest survey to determine fines } \\
\text { on trees unfelled, royalty on } \\
\text { short logs and tops, and damage } \\
\text { residual stands. }\end{array}$ \\
\hline \multirow[t]{2}{*}{ Post-Harvesting } & $\begin{array}{c}n+2 \text { year to } \\
n+5 \text { year }\end{array}$ & $\begin{array}{l}\text { Post-felling inventory of } 10 \% \\
\text { inventory using systematic-line } \\
\text { plots to determine residual } \\
\text { stocking and appropriate } \\
\text { silvicultural treatments. }\end{array}$ \\
\hline & $n+10$ years & $\begin{array}{l}\text { Forest inventory of regenerated } \\
\text { forest to determine the status of } \\
\text { the forest. }\end{array}$ \\
\hline
\end{tabular}

The newly proposed solution has the potential to improve the current method. Table 2 is the general algorithm of the new method.

Table 2. The Algorithm

of the New Proposed Method.

\section{Calculates Volume and Value} of each Tree in Logging Area

Step 1: Read idno, speciesName, speciesGroup, $\mathbf{d b h}$, height from the tree mapping pre-felling table.

Step 2: Calculate the volume. volume $=\pi(d b h / 2)^{2}$ height; 
Firstly, the proposed solution requires a tree mapping pre-felling database that contains detailed information on trees in tropical forests of logging areas. The tree mapping pre-felling database stores the position of each tree ( $x, y$ coordinate), DBH (diameter-breastheight), the tree height, species group, and species name. There are about 7650 trees in 9 hectares of forest. The following Fig. 1 displays random of 20 tree records of pre-felling data.

\begin{tabular}{|c|c|c|c|c|c|c|}
\hline idno & speciesname & $\mathrm{g}$ & $\mathrm{dbh}$ & height & $\mathrm{x}$ & $y$ \\
\hline 991 & Kelandan & G2 & 2.99 & 1.61 & 222.68 & 40.53 \\
\hline 623 & Pepauh & G4 & 23.19 & 4.87 & 162.39 & 129.96 \\
\hline 2447 & Kelandan & G2 & 23.97 & 4.11 & 127.11 & 114.13 \\
\hline 6170 & Mengkulang jari bulu & G3 & 1.93 & 2.34 & 60.35 & 216.9 \\
\hline 2535 & Pulai basong & G4 & 1.35 & 1.57 & 226.72 & 214.63 \\
\hline 919 & Giam rambai & G1 & 2.71 & 2.64 & 12.2 & 82.08 \\
\hline 671 & Otak udang & G4 & 30.18 & 17.81 & 32.62 & 234.66 \\
\hline 3569 & Jongkong & G5 & 1.34 & 1.65 & 99.34 & 10.36 \\
\hline 3821 & Asam pupoi & G3 & 14.85 & 5.28 & 222.09 & 280.6 \\
\hline 6531 & Kelumpang & G4 & 4.82 & 2.9 & 15.9 & 220.16 \\
\hline 4693 & Balau tembaga & G1 & 3.85 & 2.4 & 254.57 & 220.09 \\
\hline 820 & Jongkong & G5 & 41.56 & 16.31 & 90.15 & 6.01 \\
\hline 2369 & Buluh & G5 & 3.23 & 3 & 181.8 & 24.15 \\
\hline 7580 & Damar hitam bulu & G1 & 4.91 & 2.39 & 25.4 & 30.06 \\
\hline 6137 & Durian tupai & G3 & 3.6 & 1.74 & 248.49 & 146.96 \\
\hline 6681 & Kelandan & G2 & 4.11 & 2.65 & 27.96 & 234.91 \\
\hline 1339 & Keruing gombang & G1 & 1.08 & 2.86 & 225.36 & 232.87 \\
\hline 6880 & Merawan daun bulat & G1 & 3.48 & 2.99 & 88.78 & 59.66 \\
\hline 1101 & Gapis & G4 & 3.86 & 1.29 & 270.49 & 96.28 \\
\hline 3312 & Babai & G5 & 3.41 & 2.42 & 254.54 & 74.09 \\
\hline
\end{tabular}

Fig. 1. Trees pre-felling data.

Compares to the SMS; that only takes $10 \%$ sampling. This study records each tree in the logging area. Therefore, there are various constructive calculations, simulations, and analyses that can be performed using this tree mapping pre-felling records.

At first, before the division of the logging area into clusters, the volume (in $\mathrm{m}^{3}$ ) and value (in RM) of each tree are calculated. Next, the threshold value is determined according to the size of the logging area. The maximum allowable harvest is $30 \mathrm{~m}^{3}$ per hectare [16] and the threshold value for 9 hectares is $270 \mathrm{~m}^{3}$.

Provided with the tree coordinates; the algorithm is designed and executed to determine the logging area which later divides it into clusters. Fig. 2 shows that 9 hectares of forest with a width of $300 \mathrm{~m}$ and length of $300 \mathrm{~m}$ are divided into 36 clusters. The size of a cluster is $50 \mathrm{~m}$ in width and $50 \mathrm{~m}$ in length [17]. While Fig. 3 presents the detailed position of each cluster.

It is hard to do a comparison between tree to tree of voluminous forest data. Therefore, this study takes into consideration dividing the forest into standard clusters/plots. It appeared that it is more practical and relevant to assess and analyze when data is group and divided accordingly.

Step 9 describes that the algorithm read 20 sets of cutting regimes as shown in Table 3. The algorithm creates 20 tables for 20 cutting regimes and each table consists of 36 records for 36 clusters. Each record in the table store the cluster number, total number of trees, total volume (production), total value, and total damage of residual trees (there are about $43 \%$ of residual trees damaged after harvest [18]) of potential trees to be harvested according to the specific cutting regime.

Later, the algorithm checks and summarize across all 36 clusters from the 20 tables in Step 9 and calculates the average, accumulate, and sort: number of trees, tree volume, tree value, and damages of residual trees. These records are stored in a dedicated table (calculatedcluster).

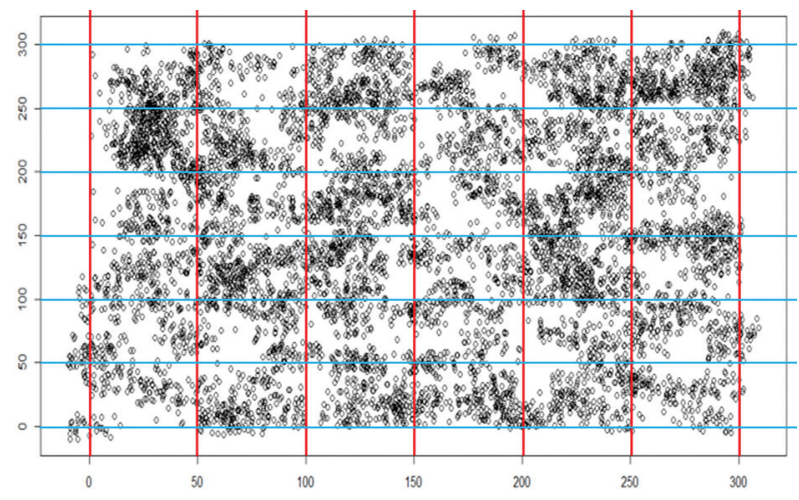

Fig. 2. 9 hectares of logging area is divided into 36 clusters.

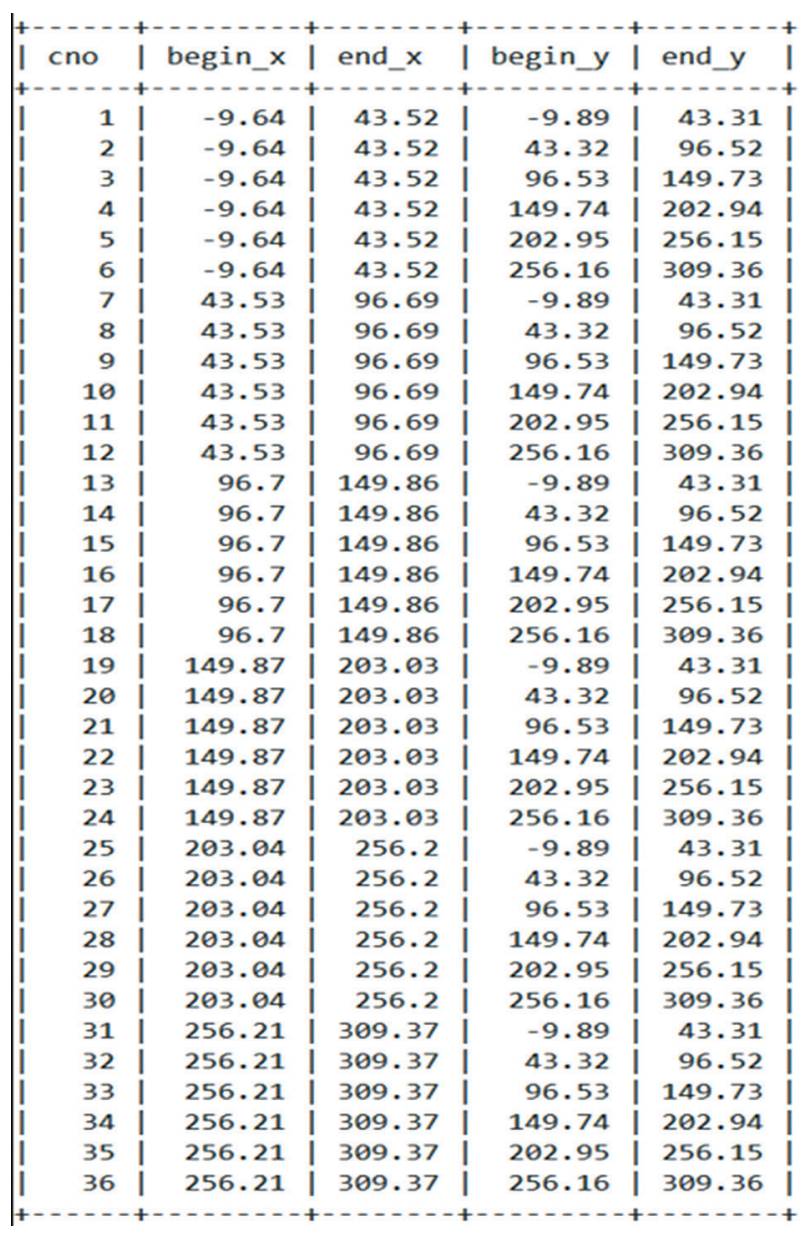

Fig. 3. Cluster number and the detail positions.

The calculatedcluster table shows the simplified records in a form of the total and average; the number of trees, value, volume, and damage of each cluster of overall 20 
sets cutting regime. Referring to this table; potential harvestable clusters are determined based on the threshold value or the maximum harvestable volume (production) as shown in the algorithm of Step 12. Meanwhile, the clusters to be preserved are updated to status $=$ 'R'.

Table 3. 20 sets of Cutting Regime

\begin{tabular}{|ccc|}
\hline No. & $\begin{array}{c}\text { Non-Dipterocarp } \\
\text { (dbh in } \mathbf{c m} \text { ) [nonDip] }\end{array}$ & $\begin{array}{c}\text { Dipterocarp } \\
\text { (dbh in cm) [dip] }\end{array}$ \\
\hline 1 & 45 & 50 \\
\hline 2 & 45 & 55 \\
\hline 3 & 45 & 60 \\
\hline 4 & 45 & 65 \\
\hline 5 & 50 & 50 \\
\hline 6 & 50 & 55 \\
\hline 7 & 50 & 60 \\
\hline 8 & 50 & 65 \\
\hline 9 & 55 & 50 \\
\hline 10 & 55 & 55 \\
\hline 11 & 55 & 60 \\
\hline 12 & 55 & 65 \\
\hline 13 & 60 & 50 \\
\hline 14 & 60 & 55 \\
\hline 15 & 60 & 60 \\
\hline 16 & 60 & 65 \\
\hline 17 & 65 & 50 \\
\hline 18 & 65 & 55 \\
\hline 19 & 65 & 60 \\
\hline 20 & 65 & 65 \\
\hline
\end{tabular}

Once the potential clusters to be harvested are finalized. The algorithm selects the best cutting regime for each potential cluster. The selection is based on the cutting regime which yields the minimum damage to residual trees. Then, in Step 13 the algorithm able to identify the potential harvestable trees according to the selected cutting regime based on the clusters to be harvested which is determined in Step 12.

In addition to the series of steps in deciding the potential harvestable trees, the new timber harvesting techniques that we introduce also determine the direction of the felling tree which yields the minimum damage volume and the minimum damage value to the residual trees. Apart from the calculation on damage volume, calculation on damage value (in monetary value) is also included.

This study able to determine which felling direction yields the minimum damage cost and minimum damage volume to the surrounding trees. This method takes into consideration of various tree species, tree value, and tree volume of the trees that surround the potential tree to be harvested. There are only a few studies that produce and analyze the damages in terms of monetary values to the residual trees.

To determine the minimum damage cost/value and minimum volume of the residual trees. Total values and volumes of all affected residual trees due to the felling direction of a harvestable tree are calculated. In this study, there are 4 options for the felling direction of a harvestable tree. Fig. 5 shows the Part 1, Part 2, Part 3, and Part 4 felling directions of each harvestable tree. The algorithm is designed and executed to verify which felling direction that produces the minimum damage cost and minimum damage volume to the surrounding of the harvestable tree.

\begin{tabular}{|c|c|c|c|c|c|c|}
\hline eno & no & $x$ & $y$ & $d b h$ & volume & value \\
\hline & & & & & & \\
\hline 9 & 10 & 57.12 & 149.28 & 61.45 & 7.79 & 3129.6 \\
\hline 9 & 26 & 54.42 & 144.11 & 38.1 & 3.27 & 1313.08 \\
\hline 9 & 33 & 75.04 & 114.7 & 38.74 & 1.54 & 837.69 \\
\hline 9 & 50 & 78.27 & 122.26 & 40.4 & 1.89 & 1031.88 \\
\hline 9 & 52 & 68.29 & 143.3 & 42.22 & 3.13 & 1257.29 \\
\hline 9 & 101 & 89.21 & 128.23 & 44.89 & 1.79 & 974.68 \\
\hline 9 & 121 & 67.78 & 145.73 & 82.45 & 8.61 & 6924.07 \\
\hline 9 & 151 & 87.62 & 100.98 & 84.61 & 4.97 & 2708.83 \\
\hline 9 & 178 & 61.32 & 118.64 & 81.57 & 12.31 & 4949.4 \\
\hline 9 & 194 & 81.81 & 121.71 & 34.06 & 1.74 & 698.85 \\
\hline 9 & 293 & 67.92 & 125.46 & 40.62 & 2.92 & 1174.22 \\
\hline 9 & 302 & 96.17 & 144.31 & 54.46 & 2.97 & 1195.81 \\
\hline 9 & 362 & 48.4 & 135.77 & 31.82 & 1.95 & 783.22 \\
\hline 9 & 365 & 56.11 & 129.79 & 86.39 & 8.48 & 3409.66 \\
\hline 9 & 377 & 65.34 & 114.73 & 80.35 & 10.65 & 4280.62 \\
\hline 9 & 396 & 51.14 & 99.05 & 51.09 & 1.97 & 792.8 \\
\hline 9 & 397 & 67.81 & 123.98 & 66.38 & 6.11 & 2456.86 \\
\hline 9 & 406 & 68.09 & 128.88 & 61.17 & 4.32 & 1735.46 \\
\hline 9 & 446 & 90.2 & 99.39 & 78.75 & 6.54 & 2627.66 \\
\hline 9 & 456 & 51.08 & 129.67 & 35.28 & 1.17 & 471.97 \\
\hline 9 & 474 & 55.07 & 120.86 & 41.78 & 3.39 & 1379.89 \\
\hline 9 & 511 & 85.96 & 127.58 & 49.24 & 2.34 & 940.81 \\
\hline 9 & 596 & 90.74 & 112.13 & 58.18 & 3.89 & 1565.67 \\
\hline 9 & 618 & 50.74 & 124.03 & 82.06 & 12.42 & 5056.27 \\
\hline 9 & 624 & 55.58 & 108.94 & 70.61 & 9.07 & 3645.75 \\
\hline 9 & 659 & 62.52 & 101.59 & 32.45 & 1.05 & 423.56 \\
\hline 9 & 662 & 87.76 & 133.37 & 33.95 & 0.76 & 307.14 \\
\hline
\end{tabular}

Fig. 4. Cluster No. 9 trees volume and value.

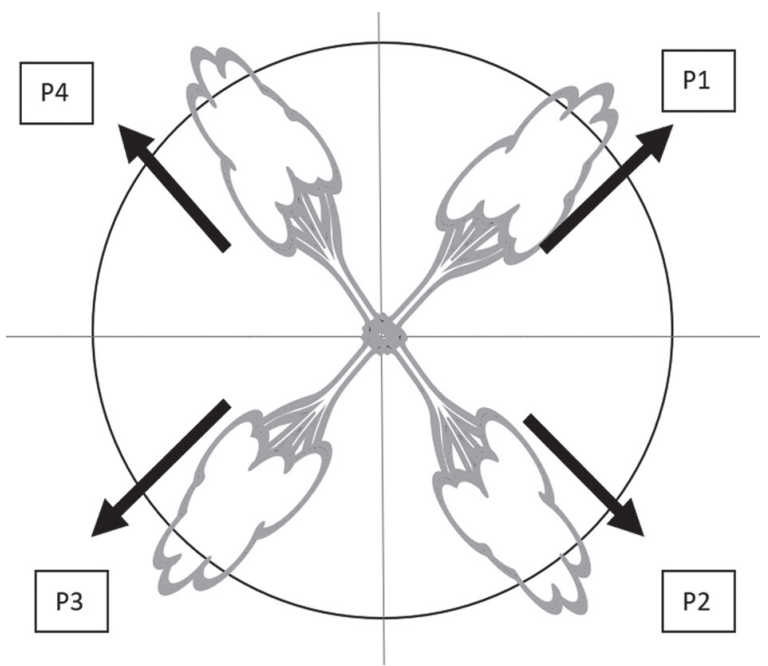

Fig. 5. The 4 options of felling. 


\begin{tabular}{|c|c|c|c|}
\hline no & speciesname & value & speciesgroup \\
\hline 1 & Giam hantu & 407 & G1 \\
\hline 2 & Kapur & 549 & G1 \\
\hline 3 & Keruing bukit & 545 & G1 \\
\hline 4 & Meranti batu & 402 & G1 \\
\hline 5 & Balau membatu jantan & 407 & G1 \\
\hline 6 & Merawan batu & 402 & G1 \\
\hline 7 & Keruing kertas & 545 & G1 \\
\hline 8 & Balau bukit & 407 & G1 \\
\hline 9 & Merawan penak & 402 & G1 \\
\hline 10 & Meranti merah muda & 732 & G1 \\
\hline 11 & Chengal & 1182 & G1 \\
\hline 12 & Meranti paya & 402 & G1 \\
\hline 13 & Mersawa durian & 626 & G1 \\
\hline 14 & Keruing ropol & 545 & G1 \\
\hline 15 & Merawan mata kucing bukit & 402 & G1 \\
\hline
\end{tabular}

Fig. 6. The tree species name, value (in RM per $1 \mathrm{~m}^{3}$ ), and tree group.

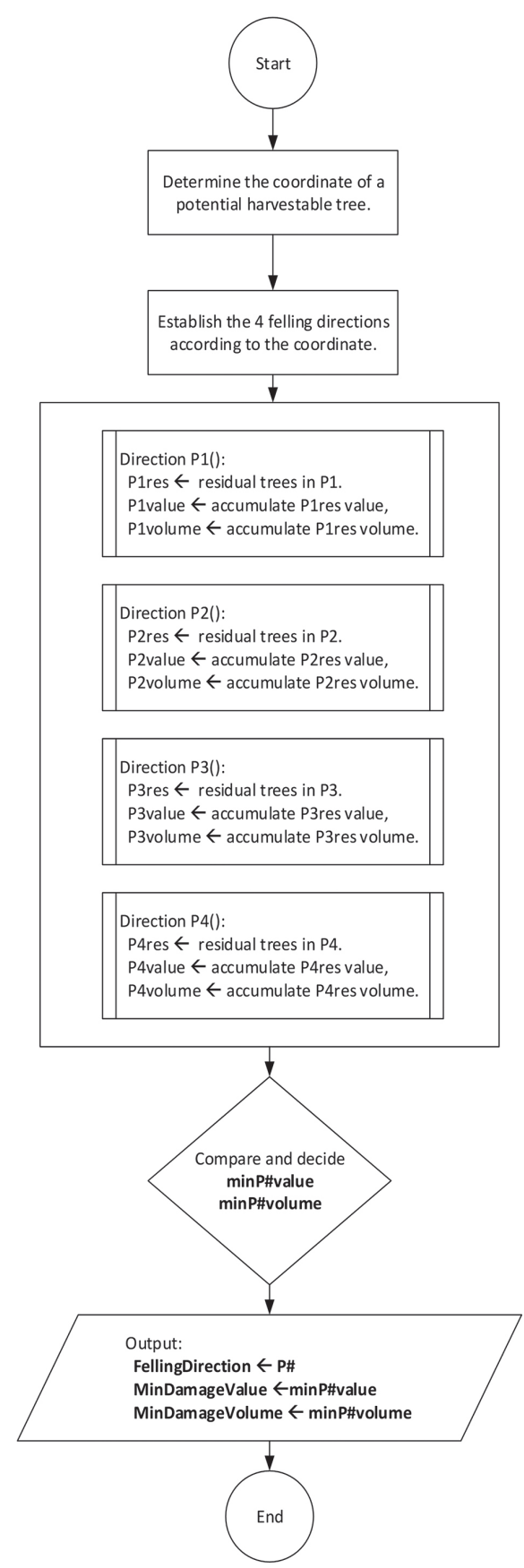

Fig. 7. Flowchart to determine minimum damage value and minimum damage volume.
For the damages calculation, at first, the algorithm will determine surrounding trees and verify them into Part 1, Part 2, Part 3, and Part 4 based on their coordinates. Later for each Part or felling direction, the algorithm calculates the total volume and value of residual trees included in it. The felling direction of the harvestable tree is based on the most minimum damage value between Part 1, Part 2, Part 3, and Part 4. The flowchart in Fig. 7 demonstrates the process of this calculation.

\section{RESULT AND DISCUSSION}

In this study, 7650 trees in 9 hectares had been recorded to determine the minimum damage value and minimum damage volume of the potential harvestable trees. The system has to select the best-felling direction before forming the calculation of minimum damage value and minimum damage volume. Fig. 8 shows that the system determines the felling direction of tree number 38; tree species name Giam Rambai is P3 (Part 3). The decision-making is based on the minimum damage volume and minimum damage value of the residual trees. This technique takes into account the various tree species, volumes, and values of surrounding affected trees.

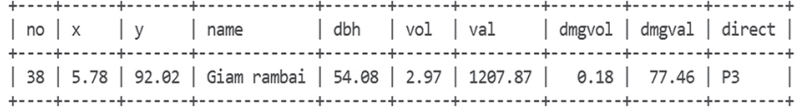

\begin{tabular}{|c|c|c|c|c|c|c|c|c|c|}
\hline \multicolumn{10}{|c|}{ mysql) select ' from realexecution fellingdirection; } \\
\hline fellino & speciesname & & & & doh & height & volume | & value | & status \\
\hline & & & овин & encest & вови & 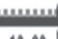 & nоми & menest & \\
\hline 38 & Giam rambai & G1 & 5.78 & 92.02 & 54.68 & 12.92 & 2.97 & 1287.87 & M30 \\
\hline 367 & Kelencen & 02 & 7.15 & 92.887 & 58.88 & 22.54 & 6.14 & 2467.21 & $7156^{\circ}$ \\
\hline 501 & Penarahan arang & Q3 & 13.44 & 82.58 & 64.37 & 22.59 & 7.35 & 2955.28 & MBO \\
\hline 767 & Jelawai mentalun & Q4 & 13.2 & 93.81 & 67,69 & 8.88 & 2.86 & 1148.27 & MBO \\
\hline 893 & Pulai penipu paya & G4 & 1.68 & 102.42 & 33.85 & 16.9 & 1.52 & 611.39 & MBO \\
\hline 901 & Giam rarbad & Q1 & $\cdot 3.11$ & 94.51 & 1.76 & 1.26 & $\theta$ & 0.12 & SE \\
\hline 992 & Giam rarbad & 01 & 10.94 & 93.36 & 3.99 & 1.4 & $\theta$ & 0.71 & $S E$ \\
\hline 903 & Giam ranbai & Q1 & 14.05 & 169.65 & 3.97 & 2.66 & $\theta$ & 1.34 & $S E$ \\
\hline 994 & Giam ranbai & 61 & 11.8 & 84.59 & 1.77 & 2.81 & $\theta$ & 0.28 & SE \\
\hline 995 & Giam ranbai & G1 & $\cdot 0.86$ & 82.21 & 4.78 & 2.11 & $\theta$ & 1.54 & SE \\
\hline 996 & Giam rambai & G1 & 13.65 & 96.82 & 1.75 & 2.92 & $\theta$ & 0.29 & SE \\
\hline 999 & Giam rambai & G1. & $\cdot 0.11$ & 85.13 & 4.64 & 1.34 & $\theta$ & 0.92 & SE \\
\hline 998 & Giam rambai & G1 & 1.54 & 98.93 & 2.64 & 1.61 & $\theta$ & 0.21 & SE \\
\hline 969 & Giam ranbai & G1 & 1.72 & 92.38 & 3.42 & 1.77 & $\theta$ & 0.66 & $S E$ \\
\hline 910 & Giam ranbaí & G1 & 12.33 & 101.63 & 2.97 & 1.46 & $\theta$ & 0.41 & SE \\
\hline 911 & Giam ranba' & G1 & -2.69 & 84 & 1.4 & 2.42 & $\theta$ & 0.15 & SE \\
\hline 912 & Giam ranba' & G1 & 7.62 & 101.79 & 4,76 & 2.27 & $\theta$ & 1.64 & SE \\
\hline 913 & Giam rarbad & Q1 & $-1,41$ & 96.23 & 4.66 & 1.83 & $\theta$ & $1.27 \mid$ & SE \\
\hline 924 & Giam rarbad & Q1 & 19,65 & 95.82 & 2.18 & 2.38 & $\theta$ & 0.36 & SE \\
\hline 915 & Giam rarbod & 91 & 15.68 & 93.5 & 1.85 & 1.85 & $\theta$ & 0.2 & SE \\
\hline 916 & Giam ranbai & 61 & 14,44 & 95.89 & 3.98 & 1.58 & $\theta$ & 0.81 & $S E$ \\
\hline 917 & Giam rambai & G1 & 9.93 & $85.23 \mid$ & 3.84 & 2.05 & $\theta$ & 0.97 & SE \\
\hline 918 & Giam ranbai & G1 & 11.77 & 180.9 & 4.9 & 1.72 & $\theta$ & 1.32 & SE \\
\hline 919 & Giam ranbai & G1 & 12.2 & 82.68 & 2.71 & 2.64 & $\theta$ & 0.62 & SE \\
\hline 928 & Giam rambai & G1 & 1.39 & 91.11 & 3.62 & 1.73 & 01 & 0.72 & SE \\
\hline
\end{tabular}

Fig. 8. Felling direction of tree number 38 .

An iteration of this algorithm is designed to calculate and determine the minimum damage volume and minimum damage value of each harvestable tree to decide 
on the tree felling direction. Next, the algorithm produces the total number of felling trees, the total value of felling trees, the total damage volume (production), and the total damage value (damage) by the cluster as shown in Fig. 9.

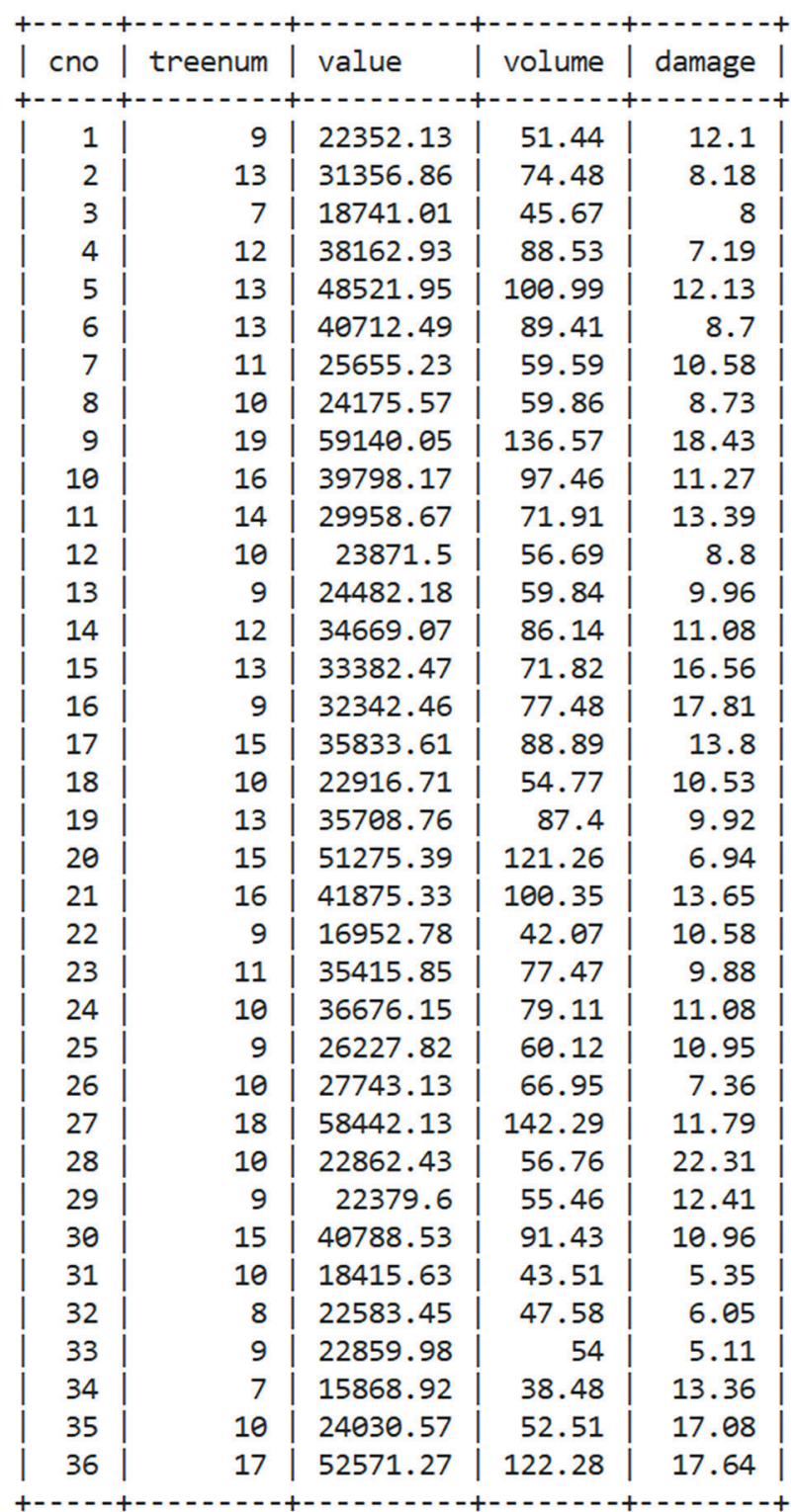

Fig. 9. Calculated the total number of felling trees, the total value of felling trees, the total damage volume, and the total damage value by clusters.

The newly proposed method introduces the logging area divided into clusters. Based on records shown in Fig. 9, the system descending sorts according to its value, production and ascending sort to its damage volume, and damage value by clusters. Then, the system accumulates those values as stated in Fig. 10.

This study proposed a new method by dividing the logging area into clusters and able to determine which tree to fell is based on the value of timber and minimum damage to the residual tree. With this new method, certain clusters will be preserved to maintain forest regeneration.
Referring to the threshold value (maximum allowable harvest $=270 \mathrm{~m}^{3}$ for 9-hectare forest), the system then calculated and only trees within 4 clusters are affected for a logging operation as shown in Fig. 11.

| cno | totaltree | totalvalue | totalvolume | totaldamage |

\begin{tabular}{|c|c|c|c|c|}
\hline 33 & 9 & 22859.98 & 54 & 5.11 \\
\hline 31 & 19 & 41275.61 & 97.51 & 10.46 \\
\hline 32 & 27 & 63859.06 & 145.09 & 16.51 \\
\hline 20 & 42 & 115134.45 & 266.35 & 23.45 \\
\hline 4 & 54 & 153297.38 & 354.88 & 30.64 \\
\hline 26 & 64 & 181040.51 & 421.83 & 38 \\
\hline 3 & 71 & 199781.52 & 467.5 & 46 \\
\hline 2 & 84 & 231138.38 & 541.98 & 54.18 \\
\hline 6 & 97 & 271850.87 & 631.39 & 62.88 \\
\hline 8 & 107 & 296026.44 & 691.25 & 71.61 \\
\hline 12 & 117 & 319897.94 & 747.94 & 80.41 \\
\hline 23 & 128 & 355313.79 & 825.41 & 90.29 \\
\hline 19 & 141 & 391022.55 & 912.81 & 100.21 \\
\hline 13 & 150 & 415504.73 & 972.65 & 110.17 \\
\hline 18 & 160 & 438421.44 & 1027.42 & 120.7 \\
\hline 7 & 171 & 464076.67 & 1087.01 & 131.28 \\
\hline 22 & 180 & 481029.45 & 1129.08 & 141.86 \\
\hline 25 & 189 & 507257.27 & 1189.2 & 152.81 \\
\hline 30 & 204 & 548045.8 & 1280.63 & 163.77 \\
\hline 24 & 214 & 584721.95 & 1359.74 & 174.85 \\
\hline 14 & 226 & 619391.02 & 1445.88 & 185.93 \\
\hline 10 & 242 & 659189.19 & 1543.34 & 197.2 \\
\hline 27 & 260 & 717631.32 & 1685.63 & 208.99 \\
\hline 1 & 269 & 739983.45 & 1737.07 & 221.09 \\
\hline 5 & 282 & 788505.4 & 1838.06 & 233.22 \\
\hline 29 & 291 & 810885 & 1893.52 & 245.63 \\
\hline 34 & 298 & 826753.92 & 1932 & 258.99 \\
\hline 11 & 312 & 856712.59 & 2003.91 & 272.38 \\
\hline 21 & 328 & 898587.92 & 2104.26 & 286.03 \\
\hline 17 & 343 & 934421.53 & 2193.15 & 299.83 \\
\hline 15 & 356 & 967804 & 2264.97 & 316.39 \\
\hline 35 & 366 & 991834.57 & 2317.48 & 333.47 \\
\hline 36 & 383 & 1044405.84 & 2439.76 & 351.11 \\
\hline 16 & 392 & 1076748.3 & 2517.24 & 368.92 \\
\hline 9 & 411 & 1135888.35 & 2653.81 & 387.35 \\
\hline 28 & 421 & 1158750.78 & 2710.57 & 409.66 \\
\hline
\end{tabular}

Fig. 10. Descending sort and accumulates trees, value, volume, and damage.

\begin{tabular}{|c|c|c|c|}
\hline cno & treenum & value & production | \\
\hline 20 & 15 & 51275.39 & 121.26 \\
\hline 31 & 10 & 18415.63 & 43.51 \\
\hline 32 & 8 & 22583.45 & 47.58 \\
\hline 33 & 9 & 22859.98 & 54.00 \\
\hline
\end{tabular}

Fig. 11. The affected clusters for logging operations.

\section{CONCLUSION}

The research introduces two new elements to be included in timber harvesting pre-felling analysis is to ensure forest regrowth which able to minimize damage as well as maintaining an adequate quantity and quality of residual stands. The first element that this research highlighted is to determine the minimum damage cost/value to the residual trees according to tree felling direction. 
In addition, to retain areas of unlogged forest for preservation; this research focused on the division of logging area into clusters where only certain clusters will be affected in a logging operation and the rest are conserved.

\section{ACKNOWLEDGMENT}

The authors would like to thank the members of the Interest Group on Research in Intelligent System (IGRIS) research group for their ideas and recommendations throughout the paper writing. Our thanks to Universiti Kuala Lumpur for full support in this research.

\section{REFERENCES}

[1] S. Chao, "Forest-Peoples-Numbers-Across-WorldFinal 0", For. Peoples Program., Vol. 1, 2012.

[2] T. R. H. Pearson, S. Brown, L. Murray, G. Sidman, "Greenhouse gas emissions from tropical forest degradation: An underestimated source", Carbon Balance Management, Vol. 12, No. 1, 2017.

[3] A. Ahmad, Q. J. Liu, S. M. Nizami, A. Mannan, S. Saeed, "Carbon emission from deforestation, forest degradation and wood harvest in the temperate region of Hindukush Himalaya, Pakistan between 1994 and 2016", Land use policy, Vol. 78, 2018, pp. 781-790.

[4] B. Bernal, L. T. Murray, T. R. H. Pearson, "Global carbon dioxide removal rates from forest landscape restoration activities", Carbon Balance Management, Vol. 13, No. 1, 2018.

[5] F. H. Susanty, "Study of recovery rates of natural forest stands after logging in East Kalimantan", IOP Conference Series: Earth and Environmental Science, Vol. 533, No. 1, 2020.

[6] E. Cedamon, G. Paudel, M. Basyal, I. Nuberg, K. K. Shrestha, "Applications of single-tree selection guideline following a DBq approach on Nepal's community forests", Banko Janakari, No. 4, 2018, pp. 104-112.

[7] J. Jamhuri et al., "Selective logging causes the decline of large-sized mammals including those in unlogged patches surrounded by logged and agricultural areas", Biological Conservation, Vol. 227, 2018, pp. 40-47.

[8] I. Saiful, A. Latiff, “Canopy gap dynamics, effects of selective logging: A study in a primary hill dipterocarp forest in Malaysia", Journal of Tropical Forest Science, Vol. 31, No. 2, 2019, pp. 175-188.
[9] M. Demies, H. Samejima, A. K. Sayok, G. T. Noweg, "Tree diversity, forest structure, species composition in a logged-over mixed dipterocarp forest, Bintulu, Sarawak, Malaysia", Transitions on Science and Technology, Vol. 6, No. 2, 2019, pp. 102-110.

[10] N. J. Naim Jemali, M. F. Abd Rhani, M. Muhammad, N. K. S. Abdul Majid, “Forest Growth Analysis of Ulu Sat Forest Reserve", IOP Conference Series: Earth and Environmental Science Sci., Vol. 549, No. 1, 2020.

[11] M. Azian et al., “Carbon emission assessment from different logging activities in production forest of Pahang, Malaysia", Journal of Tropical Forest Science, Vol. 31, No. 3, 2019, pp. 304-311.

[12] A. H. Atiqah, P. P. Rhyma, J. Jamhuri, A. W. Zulfa, M. S. Samsinar, K. Norizah, “Using Google earth imagery to detect distribution of forest cover changeIs the technique practical for Malaysian forests?", Malaysian Forester, Vol. 83, No. 1, 2020, pp. 1-15.

[13] R. Pillay, F. Hua, B. A. Loiselle, H. Bernard, R. J. Fletcher, "Multiple stages of tree seedling recruitment are altered in tropical forests degraded by selective logging", Ecology and Evolution, Vol. 8, No. 16, 2018, pp. 8231-8242.

[14] D. B. Lindenmayer, "Integrating forest biodiversity conservation, restoration ecology principles to recover natural forest ecosystems", New Forests, Vol. 50, No. 2, 2019, pp. 169-181.

[15] G. R. Cerullo, D. P. Edwards, "Actively restoring resilience in selectively logged tropical forests", Journal of Applied Ecology, Vol. 56, No. 1, 2019, pp. 107-118.

[16] R. B. de Lima et al., "Accurate Estimation of Commercial Volume in Tropical Forests", Forest Science, Vol. 67, No. 1, 2021, pp. 14-21.

[17] H. Omar, M. Hasmadi Ismail, M. Hakimi Abu Hassan, "Optimal Plot Size for Sampling Biomass in Natural, Logged Tropical Forests", Proceedings of the Conference on Forestry and Forest Products, Sunway Putra, Kuala Lumpur, 11-12 November 2013.

[18] E. van der Werf, Y. Indrajaya, F. Mohren, E. C. van lerland, "Logging damage, injured tree mortality in tropical forest management", Natural Resource Modeling, Vol. 32, No. 4, 2019, pp. 1-20. 